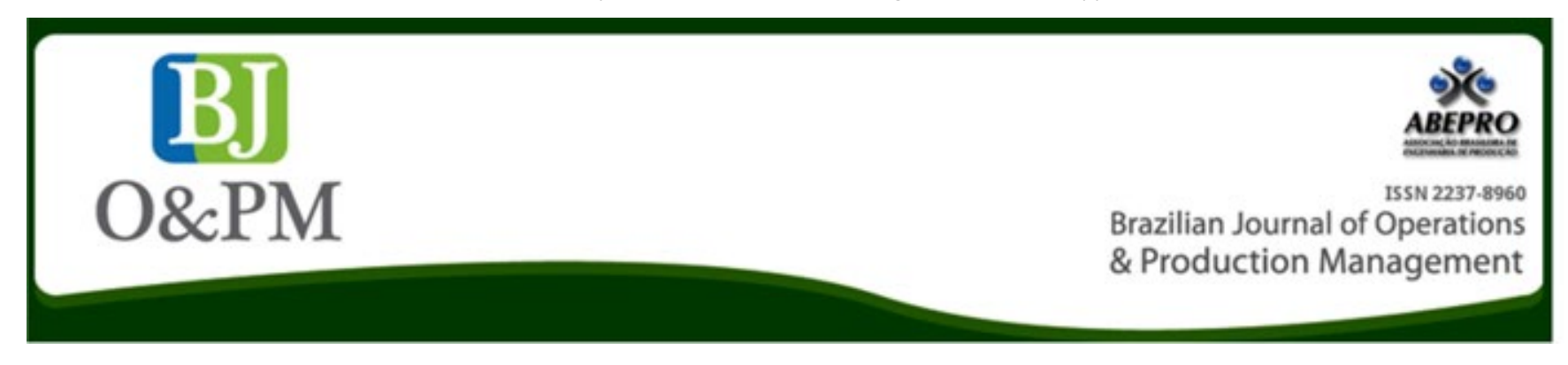

\title{
MULTICRITERIA DECISION AID TOOL FOR THE OPERATIONAL MANAGEMENT OF AN INDUSTRY: A CONSTRUCTIVIST CASE
}

\author{
Sandro César Bortoluzzi ${ }^{1}$, Sandra Rolim Ensslin ${ }^{1}$, Leonardo Ensslin ${ }^{1}$, Marcos Ottoni de Almeida ${ }^{1}$ \\ Federal University of Santa Catarina
}

\begin{abstract}
The objective of this work is to construct a performance evaluation model to provide support to a production director in the management of the productive operations of a furniture industry. In this sense, we sought through the Multicriteria Decision Aid Constructivist Methodology (i) to identify the factors considered important by the production director for evaluating the performance of productive operations, (ii) to measure each criterion of performance evaluation, (iii) to integrate the criteria to allow the evaluation of organizational performance at the tactical and strategic levels and (iv) to develop a process to manage the actions of productive operations improvement. As a research result we have a performance evaluation model for supporting the management of the productive operations. We conclude that the MCDA-C allowed for building the knowledge of the decision-maker on how to identify and measure the critical variables and manage the performance of the productive operations.
\end{abstract}

Keywords: MCDA-C.; Productive Operations; Performance Evaluation. 
Brazilian Journal of Operations \& Production Management

Volume 14, Número 1, 2017, pp. 165-182

DOI: 10.14488/BJOPM.2017.v14.n2.a4

\section{INTRODUCTION}

There is an extensive amount of literature on operational management, considering different ways in which a production system should behave, as well as methods to improve the performance (Gupta et Somers, 1996; Quezada et al., 2006; Lima, Costa et Angelis, 2008; Baldwin et al., 2010). However, the mathematical models are concentrated on a small part of the real problem, while the performance problems of production involve a wide range of factors (Hopp et al., 2007).

The need to improve the performance of the operational activities of production began after the Industrial Revolution and is intensified today mainly due to global competition and shorter product life cycles. Thus, in order to achieve success in the market, the manufacturing companies have sought new ways: (i) to reduce costs; (ii) to improve quality; (iii) to increase flexibility; (iv) to reduce the response time and; (v) to develop and introduce innovation (Hoop et al., 2007; Gupta et Somers, 1996).

In this context, the use of evaluation tools for productive operations performance in organizations has appeared to be a particularly successful way to support the manager in the identification and adoption of strategies and action plans.

However, the performance evaluation (PE) system must allow the visualization of which operational activities explain the strategic objectives, as well as their current situation and the contribution of improvement actions (Frost, 1999).

The limitations of the first-generation evaluation models, which were restricted to the financial aspects, should be overcome and all the activities that have been identified as adding value should be incorporated, whether tangible or intangible (Ensslin et al., 2010; da Rosa et al., 2012).

This systemic view of the process leading to performance evaluation $(\mathrm{PE})$ requires it to meet the six paradigms below:

1. Being constructed in a personalized way to represent the values and preferences of the managers associated with the environment specificities that it is proposed to evaluate;

2. Recognizing that, even though they experience the same environment every day, managers have no clear goals. Asking them what their goals are for the context will generate misaligned responses that the managers themselves will question later. The process used has to recognize these limitations of knowledge and help managers to build their understanding according to their values and preferences;
3. The objectives contained in the PE model are the result not only of the values and preferences of managers, but also of how they are influenced by the context in which they operate;

4. The construction of the PE model requires the continued participation of managers to ensure the construction of their knowledge in terms of the problem and to ensure legitimacy;

5. To give foundation and validity to the measurements made; they need to meet the requirements of the Theory of Measurement;

6. The model should, in each of its stages of construction and use, have the recognition of the manager in regard to the legitimacy of the constructed knowledge and its explicit representation, as well as assurance that all the instruments used have scientific recognition (Lacerda et al., 2011; Ensslin et al., 2010; Bortoluzzi et al., 2011).

Additionally, it should be clear that Organizational Performance Evaluation (OPE) is the management process used to build, establish and disseminate knowledge through the identification, organization, measurement and integration of necessary and sufficient aspects (variables) used to measure and manage the performance of the strategic objectives of a particular context of the organization (Ensslin, et al., 2010).

In this context, the question that guides this research is presented: Which variables should be considered in a model that aims to assess the performance of the productive operations of a furniture industry? To answer the research question, we present the general objective of this work: to build a model of performance evaluation of the productive operations of the industrial company Marel Furniture Industry SA.

The work is situated in the area of Operational Research (OR) named Decision Aid (DA), focusing on evaluating the production area of the furniture branch of industry. Decision Aid is the activity that, in ways we call scientific, helps to obtain elements that clarify decisions in order to provide actors with the most favorable conditions possible for the type of behavior that will increase coherence between the evolution of the process, on the one hand, and the goals and/ or systems values within which these actors operate, on the other (Roy, 1994). The contribution of this work to Operation Research is not in the mathematical area but in the operational field named DA. According to Roy (1994), "What typifies and unifies this field is that the body of knowledge produced within it stems from a project which, to my mind, is very clear. This project (which we can consider a "research programme" in Lakatos's (1974) sense of the term), could be formulated succinctly as follows: "Seeking to put science in 
the service of shedding light on managerial decisions and/ or of guiding complex processes within organized systems. When I speak of the DA-OR field, I am referring essentially to this project."

Because it is a poorly structured context that needs to be considered in a personalized way in that the manager needs support to expand and organize his understanding to explain the goals that best represent their values and preferences, we used the Multicriteria Decision Aid Constructivist Methodology (Bortoluzzi et al., 2010; Azevedo et al., 2011).

Besides this introduction, the paper presents the procedures for model construction 2; the case study in section 3; and, lastly, the final considerations of the work.

\section{PROCEDURES FOR MODEL CONSTRUCTION}

The Productive Operational Management foundations were created in a positivist paradigm, having been developed through classical Operational Research (OR), searching for the optimal alternative from a set of previously defined alternatives. Roy (1994) says in regard to this situation:

First of all, this conception of OR tends to cut it off from the milieu which nourishes it and legitimates it as something other than a branch of mathematics. Cutting off OR in this way encourages researchers to work in isolation. This results in naïve or impoverished references to managerial reality and decision-making processes. Those responsible for solving concrete problems are thus inevitably disappointed by the gap between their own expectations and the results they receive. Secondly, this conception tends to lend validity to the notion that a scientific approach to any problem dealt with in Operational Research first consists of setting forth the problem correctly and, if possible, bringing it in line with the list of standard models, then of solving the problem, and finally, after a validation phase in some instances, of implementing the solution. Even in cases where this approach is relevant (and we can cite many examples where it has proven to be fruitful), I believe that limiting Operational Research in this way is to cripple it.

Therefore, it is necessary to analyze its paradigms more deeply in order to see how it fits with the practical Productive Operational Management in which complexity, uncertainty, conflicts of interest and partial knowledge are present. This kind of analysis and questioning are vital for developing an understanding in terms of the right problem and a process that takes care of all its peculiarities (Roy,
1993; Landry, 1995).

Dvir et Lechler (2004) argue that Productive Operational Management analyzed in a positivist paradigm means nothing in situations where the initial understanding is partial and complexity and uncertainty are present. While the traditional Operational Research (OR) view of Productive Operational Management focuses on achieving performance following time and cost, the aims of the management are more focused on value for the actors involved, and therefore they are different problems.

A number of authors who use a theoretical approach based on the field of Productive Operational Management observe that the Decision Aid (DA) soft Operational Research (OR) approach has positive impacts on management when technological uncertainty is high (De Meyer et al., 2002), the long-term consequences are diffuse, the consequences are liable to be affected by external factors, the knowledge has to be developed, the management results in a huge change in the company or even in the market and the complexities of scope and the context of the management are high (Atkinson et al., 2006).

These conditions represent the complex and ambiguous world that companies face on a daily basis in a more accurate way (Pich et al., 2002). Adequate approaches are needed to deal with such a reality, as the one proposed by Thiry (2002), who defends a constructivist and personalized position to support decisions about the definition of Productive Operational Management. Bearing in mind these peculiarities and the context of Productive Operational Management, we conclude that the used of the MCDA-C, OR-DA approach as presented in Figure 1 is appropriate for dealing with Productive Operational Management.

The Multicriteria Decision Aid Constructivist Methodology (MCDA-C), by taking into account the six paradigms of decision support provided in section 1 , can be seen as appropriate for carrying out the process of performance evaluation of the productive operations of the company Marel Furniture Industry SA.

The MCDA-C methodology is divided into three main phases. Each one, in turn, is broken down into stages or steps as illustrated below in Figure 1. 


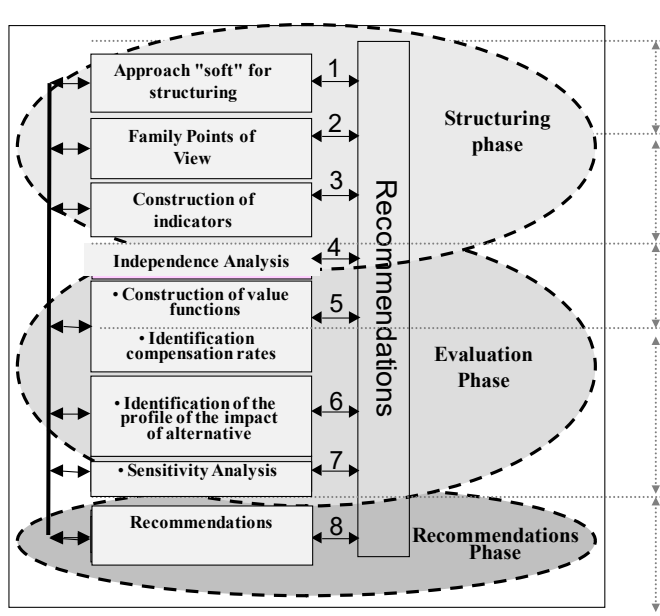

Tasks

Figure 1. Flow of activities of the MCDA-C methodology Source: Adapted from Ensslin et al., (2001)

\subsection{Structuring Phase}

\section{Step 1: Contextualization Stage}

The structuring phase aims to explain the context and build a level of understanding of the environment, which enables the problem and what is outside it to be delimited. The contextualization begins by identifying the decision context in which the actors are present, that is, those who participate, directly or indirectly, in the process in which management is performed. The actors in this process are: the decision-maker, the facilitator, the players and the affected people.

Subsequently, a label should be defined for the problem and its statement prepared. The label must contain the main focus of the work, indicate the purpose to be achieved and, finally, it should be built with a summary containing the following information: the problem; what raises the importance of the problem; the purpose of the work; what we propose to do in order to reach the goal and solve the problem and; what we hope to achieve by the end of the work (results).

This set of information constitutes the first step in the process of structuring using the MCDA-C methodology (Ensslin et al., 2001).

\section{Step 2: Value Hierarchic Structure}

At this stage, the facilitator encourages the decision-maker to talk about the context openly. This talk is recommended to be held with as few interruptions as possible. From the talk, the facilitator compiles a set of information relating to the concerns and values of the decision-maker and the properties of the context. This information is called Primary Elements of Assessment (PEAs) (Bana e Costa et al., 1999).

This information represents the aspects deemed essential by the decision-maker and makes up part of the element set that substantiates the dimensions that he has in mind when assessing the context. It is, however, still in too summarized a form. The next step thus is to expand this set of information to turn it into concepts. This is accomplished by encouraging the decision-maker to talk about it, preferentially, which direction is sought with each one of the PEAs, as well as the consequence of not achieving this purpose.

Now there is a plethora of information in the form of preferred directions pursued in the context. This set of information is now grouped by content or area of concern (Ensslin et al., 2001). Each area of concern is then composed of a set of concepts. To expand the understanding of each one of these, a cognitive map is built (Eden, 1988). Each map is then broken down into its constituent clusters and this structure is transformed into a Value Hierarchic Structure (Ensslin et al., 2001; Keeney, 1992).

\section{Step 3: Construction of Descriptors}

The hierarchical structure of value represents, at its top, the strategic goals or strategic dimensions of the decision-maker for the context, which, in the MCDA-C methodology, are called Fundamental Points of View (FPV). Its lower branches explain the tactical functions and, below these, the operating activities.

The previous stage identified what needs to be measured. Now with the help of Cognitive maps we identify the properties of the context whose properties should be measured (Bana e Costa et al., 1999). Aiming to explain the preferences of the decision-maker, in this built ordinal scale we must now specify the reference levels. The lower level will be denoted as neutral and the upper level as good (Ensslin et al., 2001). With this information, the process of building the qualitative understanding in the MCDA-C methodology is finished. Now the improvement of knowledge will take place with the introduction of more information to give greater accuracy or precision. This is achieved by transforming the obtained ordinal knowledge into cardinal knowledge.

\section{Step 4: Independence Analysis}

To continue the process of knowledge construction, the qualitative scales of the descriptors need to be transformed into cardinal and integrated scales. The MCDA-C methodol- 
ogy uses compensatory models to integrate its constituent parts and generate a global model. The MCDA-C compensatory models (Unique Synthesis Criterion Approach) require their compensation rates to be constant. In order for the compensation rates to be constant, the criteria must be preferentially independent. At this stage, the analysis of the independence of the ordinal and cardinal descriptors takes place (Ensslin et al., 2000).

The next step in the MCDA-C methodology is to transform the ordinal scales of descriptors into cardinal scales. The transformation requires the decision-maker to provide the difference of attractiveness between all the levels of the descriptor. The numerical scale that meets all the differences of attractiveness is a possible value function for the criterion or point of view. Aiming to make the value functions comparable, the neutral level of each criterion receives a score of zero, and the good level the score of one hundred.

\subsection{The Evaluation Phase}

The descriptors' construction ends the structuring phase of MCDA-C (which forms the basis for the subsequent procedures in the construction of the multicriteria evaluation model). The descriptors are essential to clarify the meaning of the FPVs, to make them more comprehensible and to avoid ambiguity. One can now proceed to the evaluation phase, which consists of the assessment of all the potential actions.

Various approaches to carrying out the evaluation of multicriteria methodologies can be used in this phase. Vincke (1992) divides these methodologies into three categories, namely: (i) Multiple Attribute Utility Theory; (ii) Outranking Methods; and, finally, (iii) Interactive Methods. Roy (1996) termed these methods: (i) the Unique Synthesis Criterion Approach; (ii) the Outranking Synthesis Approach; and, finally, (iii) the Interactive Local Judgement Approach, respectively. In this paper, Roy's terminology is used.

As the decision-makersidentify, in this specific case, that they agree that the decrease in the performance of any of the FPVs (criteria) can be compensated for by an increase in other FPVs, we realize that the most appropriate approach in this case is (i) the Unique Synthesis Criterion Approach. Thus, the overall evaluation is performed using an aggregation model, in which each variable FPV should have a value function defined as an interval of preference to avoid levels of excessive desirability as well as the opposed excessive repulsiveness. In this way, the model is built and valid for this interval in each criterion. This function can be represented as follows:

$$
\mathrm{V}(\mathrm{a})=\sum_{\mathrm{j}=1}^{\mathrm{n}} \mathrm{W}_{\mathrm{j}} \cdot\left(\mathrm{V}_{\mathrm{FPV}_{\mathrm{J}}} \cdot(\mathrm{a})\right)
$$

where:

$\mathrm{V}(\mathrm{a})$ is the global punctuation (attractiveness) of a îA;

A is the set of all possible actions;

$w_{j}$ is the compensation rate for the criterion $j$, which allows for the transformation of a unit of partial value according to each FPV into units of global value, for the established good and neutral interval;

$\left(\mathrm{V}_{\mathrm{FPVj}}(\mathrm{a})\right)$ is the impact indicator, which contains the local punctuation (attractiveness) of the actions of $A$, in relation to FPVj.

In this study, $w_{j}(j=1,[\ldots] n)$, where

$$
\sum_{j=1}^{n} w_{j}=1 \quad \text { and } \quad w_{j}>0
$$

For the FPVs to be compared, it is essential for the attractiveness and repulsiveness levels to be equivalent in all the FPVs. Thus, all the neutral and good levels must have the same partial value, hence:

$$
\left\{\begin{array}{l}
\mathrm{V}_{\mathrm{FPV}_{\mathrm{j}}}\left(\operatorname{good}_{\mathrm{j}}\right)=100 \\
\mathrm{~V}_{\mathrm{FPV}_{\mathrm{j}}}\left(\text { neutral }_{\mathrm{j}}\right)=0
\end{array}\right.
$$

In a multicriteria methodological framework, the evaluation basically consists of two stages as follows: "(1) the construction of a criterion for each fundamental point of view, that is, an evaluation model that formally represents the local attractiveness of potential actions for some evaluator(s) - single point of view evaluation, or local evaluation process; and (2) the application and exploration of a multicriteria aggregation procedure that, taking into account some information of inter-viewpoints' nature, assembles the various criteria in an overall evaluation model - overall evaluation or aggregation process" (Bana e Costa et al., 1999).

\section{Step 5. Building Value Functions}

Some approaches have been proposed for the construction of the value functions, for example, "Direct Rating" (von Winterfield et Edwards, 1986), "Bisection" (Goodwin et Wright, 1998) and "Macbeth" (Bana e Costa et al., 1999). 
Brazilian Journal of Operations \& Production Management Volume 14, Número 1, 2017, pp. 165-182

DOI: 10.14488/BJOPM.2017.v14.n2.a4
This study is based on the MACBETH methodology (Measuring Attractiveness by a Categorical Based Technique). Through its simplification, it can overcome the difficulties stemming from the questioning process. The actor just has to elaborate absolute judgements on the attractiveness difference between two actions (Bana e Costa et al., 1999).

The MACBETH questioning procedure consists of asking the actor the following question: "Given the impacts $i_{i}(a)$ and $i_{i}(b)$ of two potential actions $\underline{a}$ and $\underline{b}$ of $A$ according to a FPV ${ }_{j}$, 'a' being judged more attractive (locally) than ' $\underline{b}$ ', is the attractiveness difference between ' $\underline{a}$ ' and ' $\underline{b}$ ': 'indifferent'; 'very weak'; 'weak'; 'moderate'; 'strong'; 'very strong' or 'extreme'?".

During this questioning process, the analyst fills in a triangular sub-matrix superior to the $n \times n$ matrix, according to the answers given by the actors from the semantic categories. Then MACBETH finds (by linear programming) the cardinal scale that best represents the actors' absolute judgements.

\section{Step 6. Identification of the Compensation Rates}

Various approaches have been proposed for the determination of the compensation rates, among them the classic "trade-off procedure" (Keeney, 1992), the "swing procedure" (von Winterfield et Edwards, 1986) and MACBETH (Bana e Costa et al., 1999). Again, here, the MACBETH methodology is used.

The determination of the compensation rates $\left(w_{j}\right)$ (that is, the normalized cardinal scale of the value judgement among the FPVs), is carried out in three different timescales. The first consists of identifying the alternatives (Figure 7). The second consists of ordering the alternatives (Figure 8). The third consists of constructing the semantic matrix of value judgement (Figure 9) on the same basis as that used for the construction of the value functions. The only difference is the addition of a fictitious action with a neutral impact on every FPV, which will be used as an anchor (point 0 of the scale). These three timescales, ordering of the alternatives and construction of the semantic matrix will be discussed next (Figures 7, 8 and 9).

\section{Step 7: Diagnosis and Status Quo (SQ)}

The built knowledge now allows us to visualize numerically and graphically the profile of the current situation and the consequences of actions to promote its improvement. The model built by C-MCDA methodology makes possible an explicit and reasoned evaluation, highlighting the strengths and weaknesses and thus the opportunities for improvement.

\subsection{The Recommendations Phase}

\section{Step 8: Formulation of Recommendations}

The knowledge generated allows the decision-maker to visualize graphically and numerically for each criterion whether the performance is "excellent", "normal" or "compromising". On the other hand, the scale gives him/her information on which of the performances is superior to the current one. This, combined with the decision-maker's additional knowledge about the context, will enable him or her to identify actions to improve and predict the level at which the context will be if the performance is implemented.

Then, the model will inform the decision on the contribution to the criterion and to the global context. Thus, multiple actions can be generated and ranked in the order of contribution. This phase is called the recommendation phase.

\section{CASE STUDY}

\subsection{Structuring Phase}

\section{Step 1: Contextualization Stage}

The researcher began by holding meetings with the individual responsible for the company production area at Marel Furniture Industry SA. The organization wanted a process through which to conduct substantial operational management in a clear, reasoned and participative way, as perceived by the Director of Production. The subsequent interviews showed the following:

Chart 1. Actors involved in the performance problem of business operations

\begin{tabular}{|c|c|}
\hline Decision-Maker & Production Director \\
\hline Intervenients & Other directors \\
\hline Facilitators & Authors of the work \\
\hline Affected & $\begin{array}{c}\text { Employees, suppliers, clients, financial institu- } \\
\text { tions and trade unions }\end{array}$ \\
\hline
\end{tabular}

Label: Performance Evaluation of the Production Operations of Marel SA Company.

\section{Summary:}

The person responsible for the Productive Operational Management wants to improve the performance according to his perception, but it is not clear to him how to expli- 
cate such knowledge. This understanding is important for: achieving consistency in his decisions and actions; disseminating the knowledge of what is important; and being able to highlight the good and the bad results. Developing the knowledge of the decision-maker and presenting it in the form of a model is the objective of the decision-maker. Given the complexities of the context, the multiple actors with different powers and abilities and the conflicting interests of those involved, the MCDA-C methodology will be used.

As a result, the decision-maker hopes to build knowledge that allows him to define clearly what is important, with scales to measure the performance and compensation rates needed to establish an order of contribution and to show the strengths and weaknesses of the properties perceived as important by the decision-maker.

\section{Step 2: Value Hierarchical Structure}

Having legitimized the context, we continued with the process of interviews with the decision-maker.

We asked the decision-maker to identify the concerns inherent in the productive sector of the company. We tried to motivate the decision-maker to talk about all the aspects that he believed to be important, and reassured him that he should not worry about redundancy. In this case, the interviews with the decision-maker and the analysis of the strategic planning of the company produced 106 Primary Elements of Assessment (PEA).

Thus, Chart 2 below shows some of the Primary Elements of Assessment (PEA) identified in this step:

Chart 2. Examples of Primary Elements of Assessment (PEA)

\begin{tabular}{|c|c|}
\hline 1 - Fixed costs & $\begin{array}{c}5-\text { Partnership relations with } \\
\text { suppliers }\end{array}$ \\
\hline 2 - Investments & 6 - Loading management \\
\hline $\begin{array}{c}3-\text { Time of raw material and } \\
\text { supplies }\end{array}$ & 7 - Internal processes \\
\hline $\begin{array}{c}4-\text { Machinery and equipment } \\
\text { with too much use time }\end{array}$ & 8 - Lead time \\
\hline
\end{tabular}

Source: Research data.

Following this, the concepts oriented to action, were prepared with the decision-maker. In this process, each PEA undergoes an expansion of knowledge about the concerns previously mentioned in order to identify the direction of preference of each PEA and its psychological opposite. Each PEA was discussed with the decision-maker in order to build knowledge regarding which aspects should be considered in a model of performance evaluation of the productive operations of the company.
The concepts were obtained from the interviews with the decision-maker, when he was asked to speak in detail about each PEA. In Chart 3, are some samples of concepts oriented to action, where the ellipsis (...) should be read as "instead of" and corresponds to the psychological opposite.

Chart 3. Examples of concepts (objectives)

95 - Having a process of preventive maintenance... expecting the equipment or machinery to break down and undermine productivity

131 - Seeking to improve the company productivity ... failing to meet the market demand

132 - Seeking to upgrade the manufacturing park with new technologies ... using outdated technologies

141 - Seeking to improve the internal processes to improve plant productivity... having low productivity

180 - Ensuring improvement in productivity through production management... and reduce plant productivity

181 - Seeking to improve productivity through reduced time for each batch... and reduce plant productivity

182 - Improving the production system for application to improve productivity... keeping inventories increasing financial costs

Source: Research data.

Each concept was built from a PEA and the speech of the decision-maker connecting the PEA to the Productive Operational Management. The examination of the set of concepts constructed allowed the decision-maker to group them into areas of concern in the production area, as shown in Figure 2:

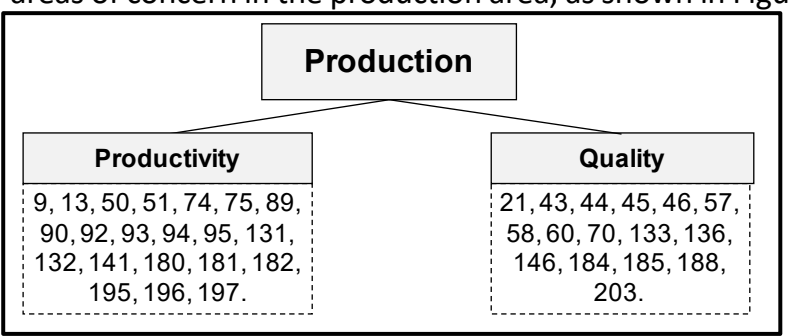

Figure 2. Clusters of concepts in areas of concern in the production area FPV Source: Research data.

It is noticeable that the scale "production" consists of two areas: productivity and quality. With the identification of Primary Elements of Evaluation, the preparation of the action-oriented concepts and the grouping of concepts, it is possible to start the next phase of the process of structuring the performance evaluation model, that is, the construction of cognitive maps and the tree of Fundamental Points of View (FPV).

This stage in the structuring phase consists of various steps, defined as: (i) the construction of the cognitive map; (ii) the construction of a family of Fundamental Points of View (FPVs); and (iii) the construction of descriptors (performance indicators, ordinal scales). 
According to Bana e Costa et al. (1999), the first concern that the analyst is confronted with is to understand "what the problem is" from the perspective of the actors involved in a given situation. To aid this understanding, many tools have been developed by researchers in the field, which are able to represent schematically the construction of the problematic situation. In this study, the technique identified as the most appropriate was the cognitive map. There are many types of cognitive map (Fiol et Huff, 1992). This article follows the cognitive mapping suggested by Eden et al., (1983) and Eden (1988) - depicting causal or influential relations - for its adequacy in the structuring of multicriteria models.

Cognitive mapping involves several stages, the first being the establishment of a label for the problem. In the specific case of the present study, such a label is defined as "Performance Evaluation of the Production Operation Management of Marel SA Co.". The labelling of the problem is the starting point of the mapping. From this labelling, the technique of brainstorming is utilized with a view to identifying those aspects felt to be relevant by the actors involved. The next stage is, then, the use of a question scheme (in this paper, Keeney's (1992) scheme was used) through which a concept generates another concept, this new concept being the end concept. In the cognitive mapping, we assumed that the links between concepts only show an influence relationship (Cossette et Audet, 1992). This process continues until both those concepts found to be strategic and those concepts liable to be measured are identified.

This procedure was used in this study, resulting in a map as presented for the dimension or area of concern "productivity", as shown in Figure 3.

It is apparent that the "productivity" area map involves two clusters: the first related to aspects of "improvement of the assets' use" and the second related to aspects of "production management".

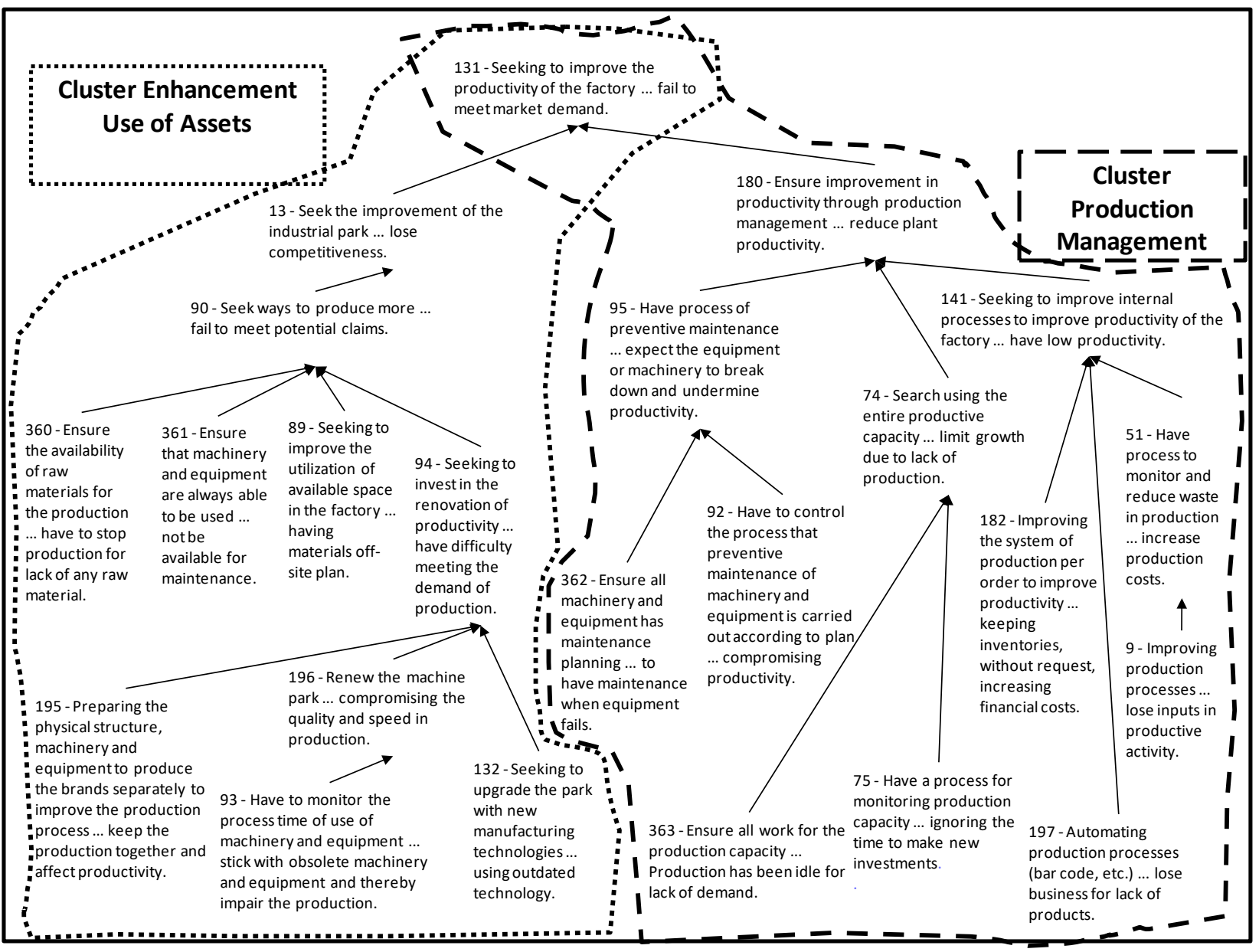

Figure 3. Cognitive map of the productivity dimension 


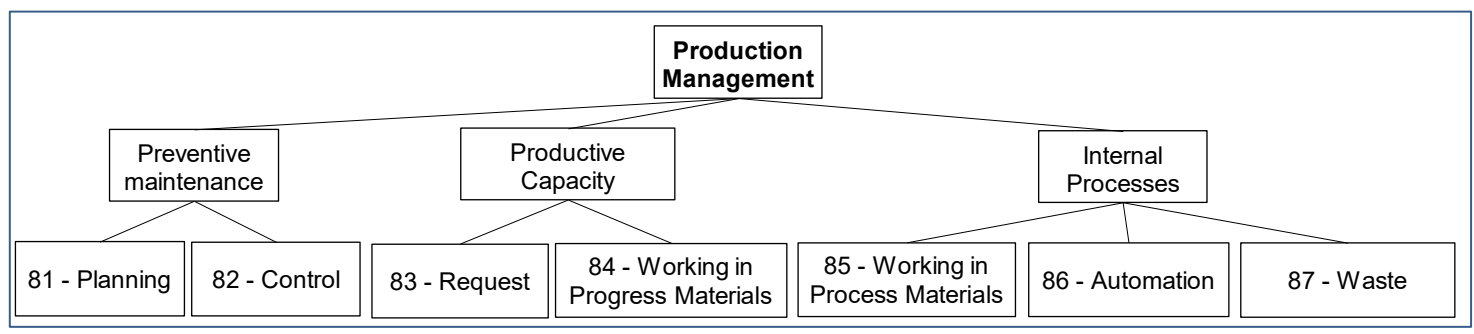

Figure 4. Value Hierarchical Structure for the FPV "production management"

Source: Research data.

From the cognitive map it is possible to continue to the next structuring phase, that is, the building of the Hierarchical Structure of Value and also the construction of descriptors.

In this stage of the structuring phase, the transition was made from the cognitive map to the Hierarchical Structure of Value and the construction of descriptors. An FPV is said to be operational when the impact of the "status quo" as well as every possible potential action can be measured in relation to it. Such an operational function is called a descriptor of impact of the actions, according to Bana e Costa et al. (1999). On many occasions, for an FPV to become operational, it is necessary to decompose it into Elementary Points of View (EPV); see Figure 4. These are merely the explanation and detailing of the FPV with which they are associated (Bana e Costa et al., 1999).

It is noteworthy that the descriptors and also the level of impact associated with them are built based on information in the cognitive maps. The opposite poles of the maps help us to define the lowest level of impact of a descriptor, and the present poles help us to define what the decision-maker considers to be the level of excellence. The Hierarchical Structure of Value and descriptors for the FPV "production management" are shown in Figure 4:

\section{Step 3: Construction of Descriptors}

Once the EPVs that comprise the FPV "production management" were explained, the construction of the descriptors was initiated. To build the descriptors we sought information from the cognitive map in Figure 3, the cognitive map of the productivity dimension. As a result the descriptors presented in Figure 5 appeared. The Hierarchical Structure of Value of the FPV "production management" as presented in Figure 5 also shows the reference levels of each descriptor. The neutral and good levels have already been incorporated into this representation.

When a literature collation is carried out with the developed model, it is noticed that, in the structuring phase, the considerations of the manager and the operational proper- ties are met. Value considerations explain the perception of the manager regarding how it contributes to the organization's strategic objectives, which are outside his control (Kaplan et Norton, 2000). Another element of the developed model, which can be checked at every structuring stage, is the consideration of the intangibles. The intangible aspects are deemed in the literature as essential in the current context in which companies operate, since the only financial aspects are no longer responsive to the needs of the managers (Kaplan et Norton, 2000).

In addition to these elements, the developed model includes, in the construction of cognitive maps phase, the possibility of checking the alignment between the operational objectives and the goals considered as strategic by the organization. In the cognitive maps, it is possible to identify the cause and effect relationship between operational objectives and strategic goals. According to the papers that comprise the literature review, these aspects, which link strategy to operation and include the existing links, are of fundamental importance for the successful implementation of a system of performance evaluation (Kaplan et Norton, 2000).

In the context of the present study, given the characteristics of the Production Operation Management (described above), the decision-maker was now interested in identifying two basic additional issues: (i) the Production Operation Management's individual profile, with the purpose of identifying actions to improve the performance; and (ii) the global performance profile, to enable the ordering of the generated improvement actions. These can both be achieved via an evaluation process, described below.

This step in the structuring also contributed to improving the communication among the decision-actors and it was fruitful for the later design of strategic actions.

\section{Step 4: Independence Analysis}

In order to achieve a cardinal local and global evaluation the qualitative scales of the descriptors must be transformed into cardinal scales and then integrated. The MCDA-C uses a compensatory model to build the global evaluation model. 


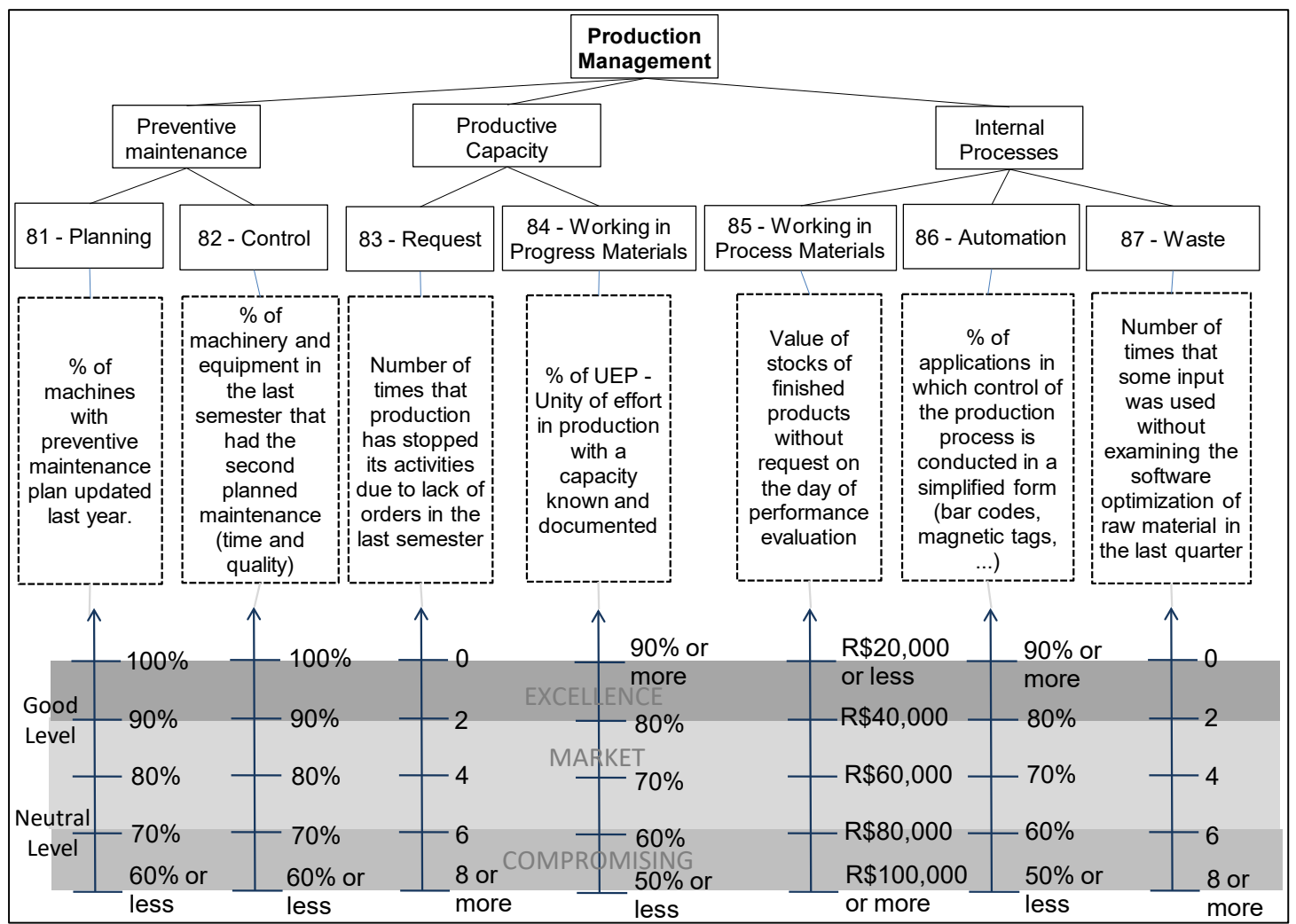

Figure 5: Value hierarchic structure and descriptors for the FPV "production management" Source: Research data.

This model assumes that the conversion rates used in the integration are constant. To achieve this condition, the criteria must be independent (Ensslin et al., 2010).

All the criteria were analyzed to check whether preferential independence exists in the interval established by the neutral and good levels (Ensslin et al., 2001).

\subsection{The Evaluation Phase}

The evaluation phase is carried out by taking the following steps: (i) the construction of value functions for each Elementary Point of View (EPV), (ii) the determination of replacement rates and (iii) the completion of the global evaluation and impact profile of the status quo.

\section{Step 5: Value Functions}

This first step consists of transforming the ordinal scales into cardinal scales; this can be performed by identifying through the judgement of the decision-makers the difference terms of in attractiveness between all the levels of descriptors. This step is performed with the help of the Macbeth software, which constructs a value function for each descriptor. We note that the value functions are based on anchoring levels: 100 points (good level) and 0 points (neutral level). This process is illustrated in Figure 6.

From the identification of cardinal scales, the decision-maker understands the difference in terms of attractiveness between moving from one impact level to another for each performance indicator. However, such a set of information alone is not sufficient to accomplish the global evaluation of performance. Thus, we sought to determine the compensation's rates through the decision-maker's perception, as discussed below.

\section{Step 6: Compensation Rates}

Compensation rates will allow the additive aggregation of criteria, enabling the global evaluation of performance. To calculate the compensation rates, fictitious potential actions are created, which represent the contribution of the transition from the neutral level to the good level in each of the criteria as well as a reference action with neutral performance for all the points of view, as shown in Figure 7: 


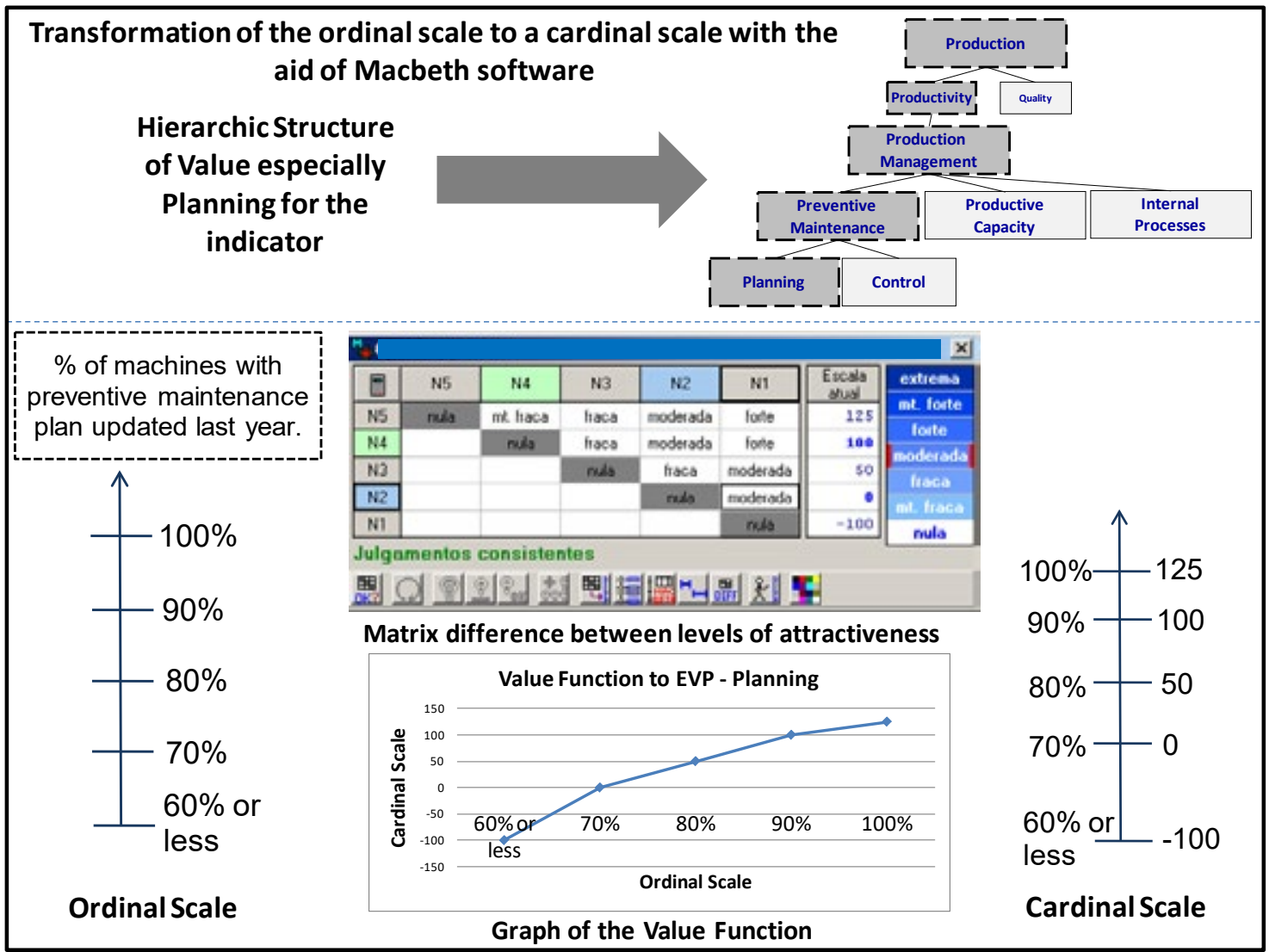

Figure 6: Illustration of the transformation of an ordinal scale to a cardinal scale (value function)

Source: Research data.

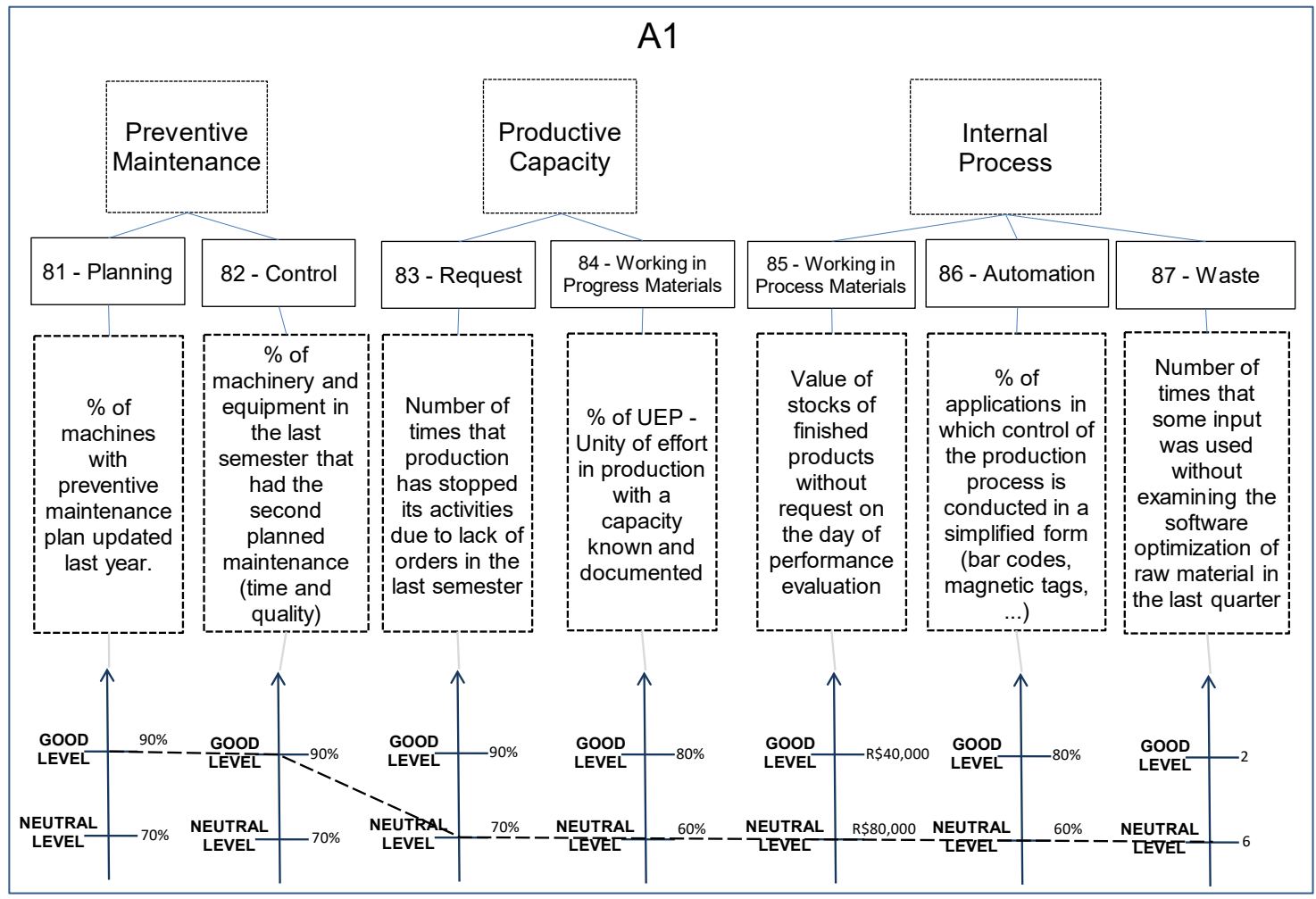



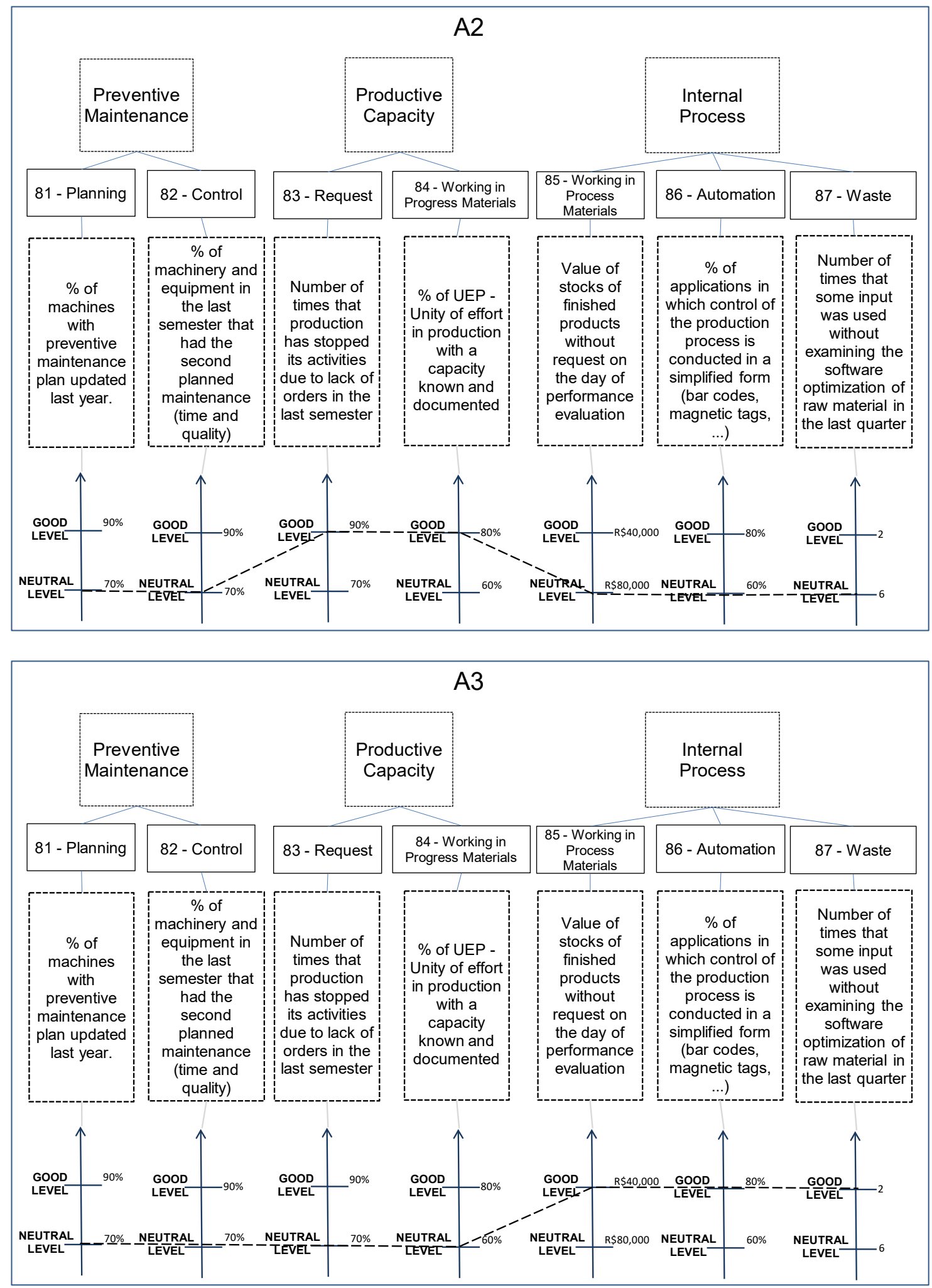


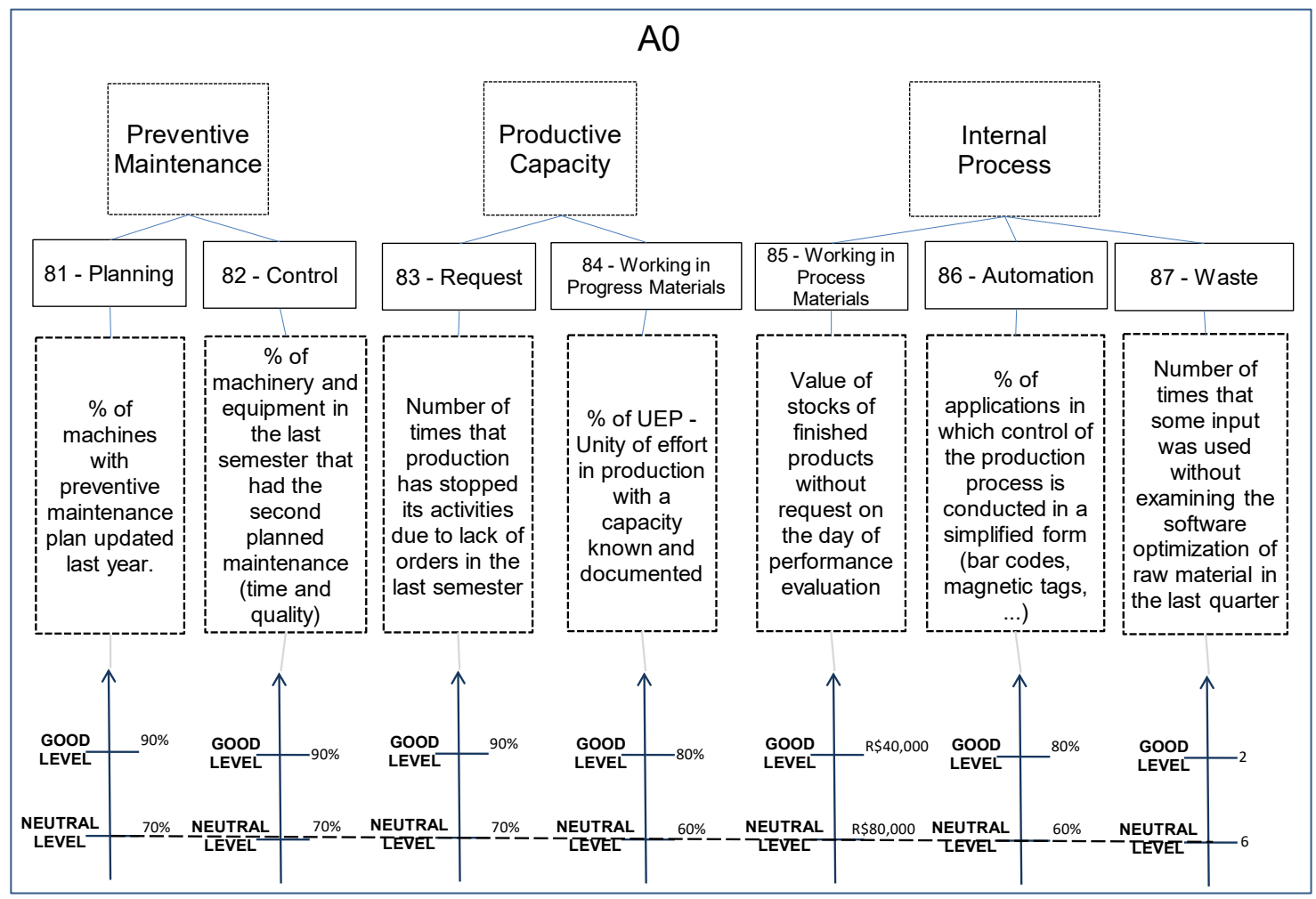

Figure 7. Potential alternatives for determining the compensation rates indicating the respective neutral and good levels Source: Research data.

The first step in calculating the substitution rates consists of ranking the alternatives through the array of Roberts (1979), which consists of asking the decision-maker his or her preference between alternatives. This can be seen in Figure 8:

\begin{tabular}{|c|c|c|c|c|c|c|}
\hline & $\mathrm{A} 1$ & $\mathrm{~A} 2$ & $\mathrm{~A} 3$ & $\mathrm{~A} 0$ & SOMA & ORDEM \\
\hline $\mathrm{A} 1$ & & 0 & 0 & 1 & 1 & $3^{\circ}$ \\
\hline $\mathrm{A} 2$ & 1 & & 1 & 1 & 3 & $1^{\circ}$ \\
\hline $\mathrm{A} 3$ & 1 & 0 & & 1 & 2 & $2^{\circ}$ \\
\hline $\mathrm{A} 0$ & 0 & 0 & 0 & & 0 & $4^{\circ}$ \\
\hline
\end{tabular}

Figure 8: Roberts's array representing the contribution of the alternatives to moving from the neutral level to the good in each viewpoint considered

Source: Research data.

Subsequently, the information held in the hierarchy above is inserted and the decision-maker is asked to consider pairs of potential actions. This step can be seen in Figure 9:

This procedure was performed for every model of performance evaluation and, as a result of these considerations, compensation rates that reflect the perceptions and values of the decision-maker were obtained. Figure 10 shows the evaluation model for the FPV "production management" with the compensation rates and the profile of the status quo.

\begin{tabular}{|c|c|c|c|c|c|}
\hline & A2 & A3 & A1 & AO & $\begin{array}{l}\text { CURRENT } \\
\text { SCALE }\end{array}$ \\
\hline A2 & no & weak & moderate & very strong & 50.00 \\
\hline $\mathrm{A} 3$ & & no & weak & moderate & 33.00 \\
\hline $\mathrm{A} 1$ & & & no & weak & 17.00 \\
\hline A0 & & & & no & 0.00 \\
\hline
\end{tabular}

Figure 9: Compensation rates generated by the M-MACBETH software comparing the difference in terms of attractiveness between the alternatives Source: Research data.

Step 7: Current Situation of the Status Quo (SQ)

Global Evaluation, Impact Profile and Assessment of the Status Quo

The current situation presented a performance of 40 points for the scale constructed, and therefore was regarded as competitive as perceived by the decision-maker. The evaluation and graphical representation are shown in Figure 11.

Figure 11 shows, in this way, the consequences of the current situation for those aspects deemed by the decision-maker to be necessary and sufficient for evaluating the 


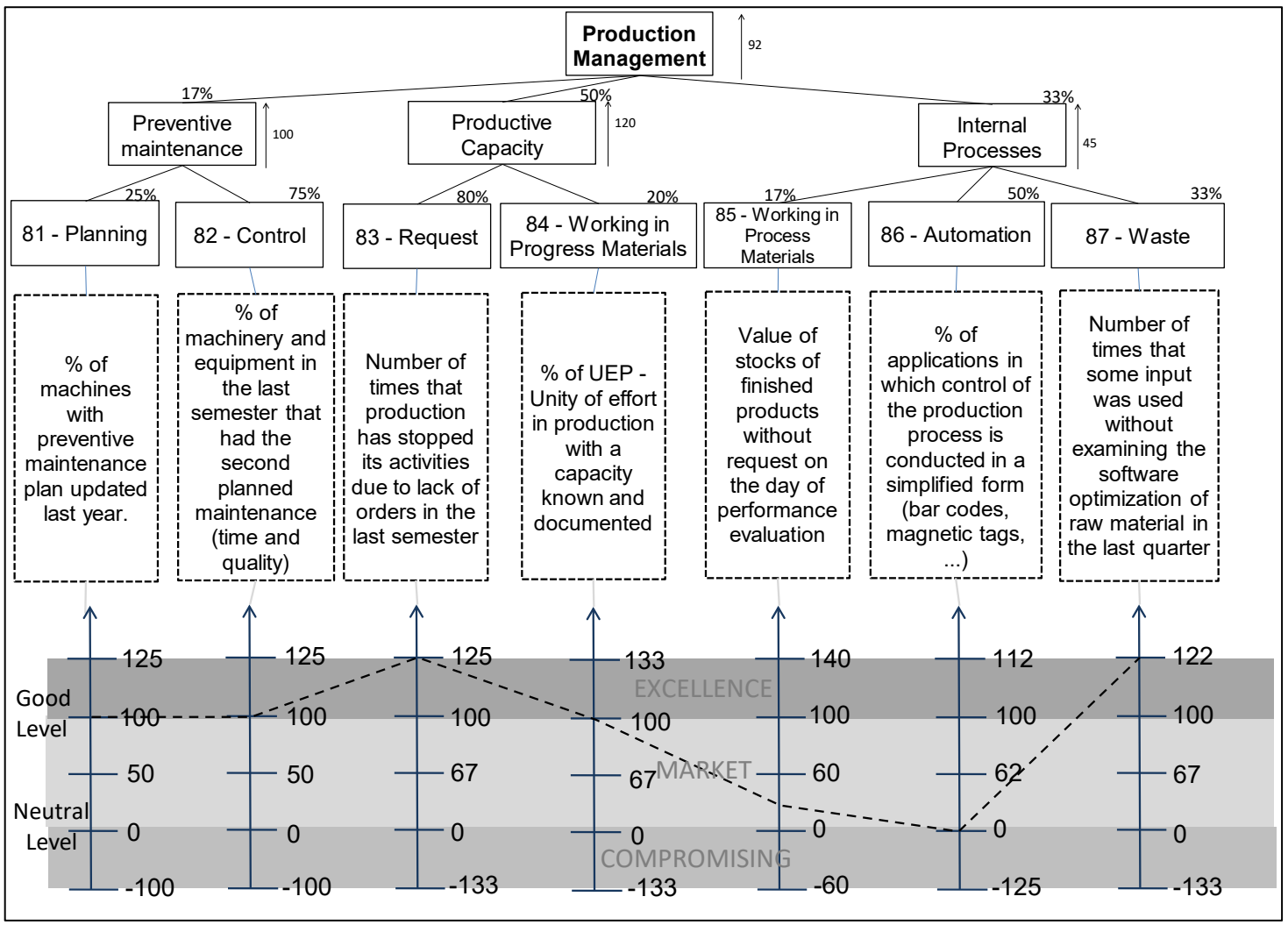

Figure 10: Value hierarchic structure and status quo for the FPV "production management"

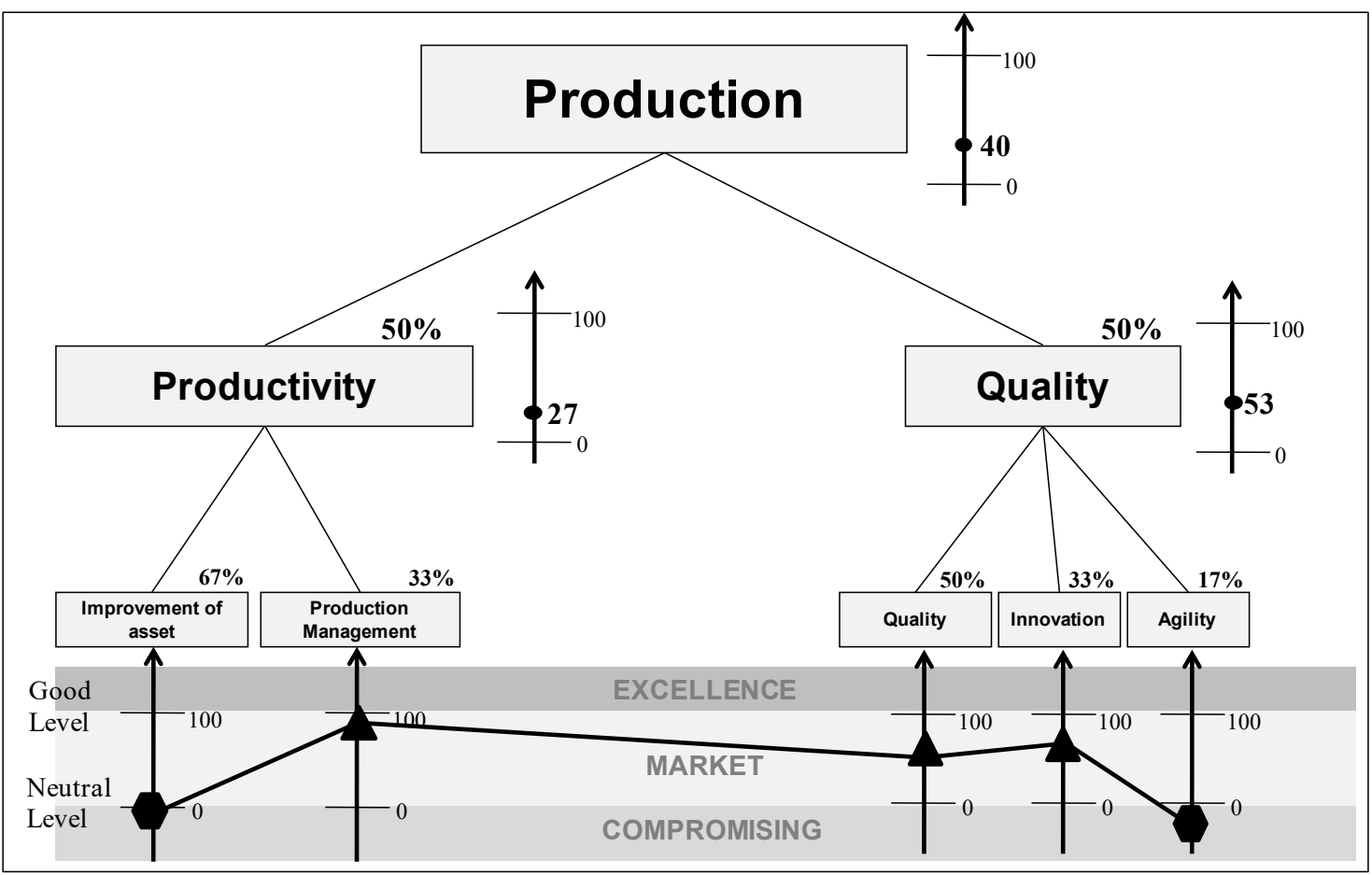

Figure 11. Impact profile of the status quo and identifying strengths and weaknesses of the production Source: Research data. 
industry operating system. Additionally, it shows the points at the market level and the weak points.

Figure 11 presents the evaluation of the current performance of the productive operations of Marel Furniture Industry SA, as well as the impact profile of the status quo.

The overall evaluation of 40 points is formed by the sum of each FPV. Thus, the overall equation of the FPV model is shown below:

$V(\alpha)=0.3350 * V_{P V B 1}(\alpha)+0.1650 * V_{P V 72}(\alpha)+0.2525 * V_{P V F 1}(\alpha)+0.1650 * V_{P V E 4}(\alpha)$ $+0,0850 * V_{\text {PVFg }}(\alpha)$

In the equation, the constants are the results of the product of the rates in the rising chain, i.e. the first value 0.3350 corresponds to $0.67 * 0.50$, and so on.

Thus, for each FPV, we will have a model in the form of Equation 5:

$$
V_{P V F_{k}}(a)=\sum_{i=1}^{n_{k}} w_{i, k} \bullet v_{i, k}(a)
$$

For the $\mathrm{FPV}_{2}$ used in the illustrations, we will have:

$$
\begin{aligned}
& V_{\text {DVF2 }}(\alpha)=0,17\left\{0,25 \cdot V_{\text {planning }}+0,75 \cdot V_{\text {Control }}\right\} \\
& +0,50\left\{0,80 * V_{\text {Request }}+0,20 * V_{\text {Astompaniment }}\right\} \\
& +0,33\left[0,17 \times V_{\text {Materiats in Process }}+0,50 \times V_{\text {kutomarion }}+0,33\right. \\
& \text { * } \left.V_{\text {warte }}\right\}
\end{aligned}
$$

With the completion of the evaluation phase of the model, the decision-maker could evaluate in a graphical and numeric form the impact profile of the status quo and the proposed alternatives to improve the overall performance. The conditions are perceived by him as essential to the Production Operation Management. The models constructed by the MCDA-C methodology make possible an explicit evaluation in numerical and/ or graphic form, facilitating the identification and understanding of the intensity of the strong as well as the weak points of the alternatives under evaluation. In the steps of the evaluation phase, the particularities of the productive operations of the company Marel Furniture Industry SA were taken into account through the decision-maker's perception of the company.

\subsection{Recommendation Phase}

\section{Step 8: Formulation of Recommendations}

The recommendation phase allows strategies to be built that can improve the company performance, in accordance with the decision-maker's perception. Accordingly, through the interaction between the decision-maker and the facilitator, and by reading the status quo established in the evaluation phase, we decided to create strategies that facilitate the raising of performance of the productive operations of the company.

In this context, we identified the tactical objectives (management) and operational objectives that are performed below the neutral level and also those for which the performance is at the market level, but for which the decision-maker believes improvement strategies should be developed. Also, we sought to prioritize the goals with a greater contribution to the overall performance through compensation rates.

With the successful implementation of the strategy, the company Marel Furniture Industry SA would achieve better performance in terms of productive operations if the overall performance changed from 40 points to 61 points, as can be seen in Figure 12.

It uses the PE model to develop strategies to improve and develop recommendations for the company to achieve superior performance. This can be accomplished in several ways: (i) identifying the performance of each indicator to meet a specific performance for a given variable, (ii) establishing different strategies to identify the impact on the overall evaluation of performance, (iii) analyzing the cost versus the benefit of implementing a strategy, (iv) prioritizing the strategies and actions intended to be implemented by means of the goals with higher contribution rates (compensation) and (v) evaluating the performance at every level (strategic, tactical and operational).

It is noted that the recommendations phase is aligned with the theoretical affiliation of the evaluation of organizational performance, because it can lead the performance management in the strategic, tactical and operational levels, based on the strengths and weaknesses, and suggests actions for improvement (Ensslin, et al., 2010).

\section{CONCLUSIONS}

The objective of this work was to construct a performance evaluation model to support a production director in the management of the productive operations of a furniture industry. The contribution of this work was to the Operation Research field, not in the mathematical area but in its operational field named Decision Aid, putting science in the service of shedding light on managerial decisions and guiding the complex processes within organized systems. With these concepts in mind the research aimed at constructing a performance evaluation model to support the 


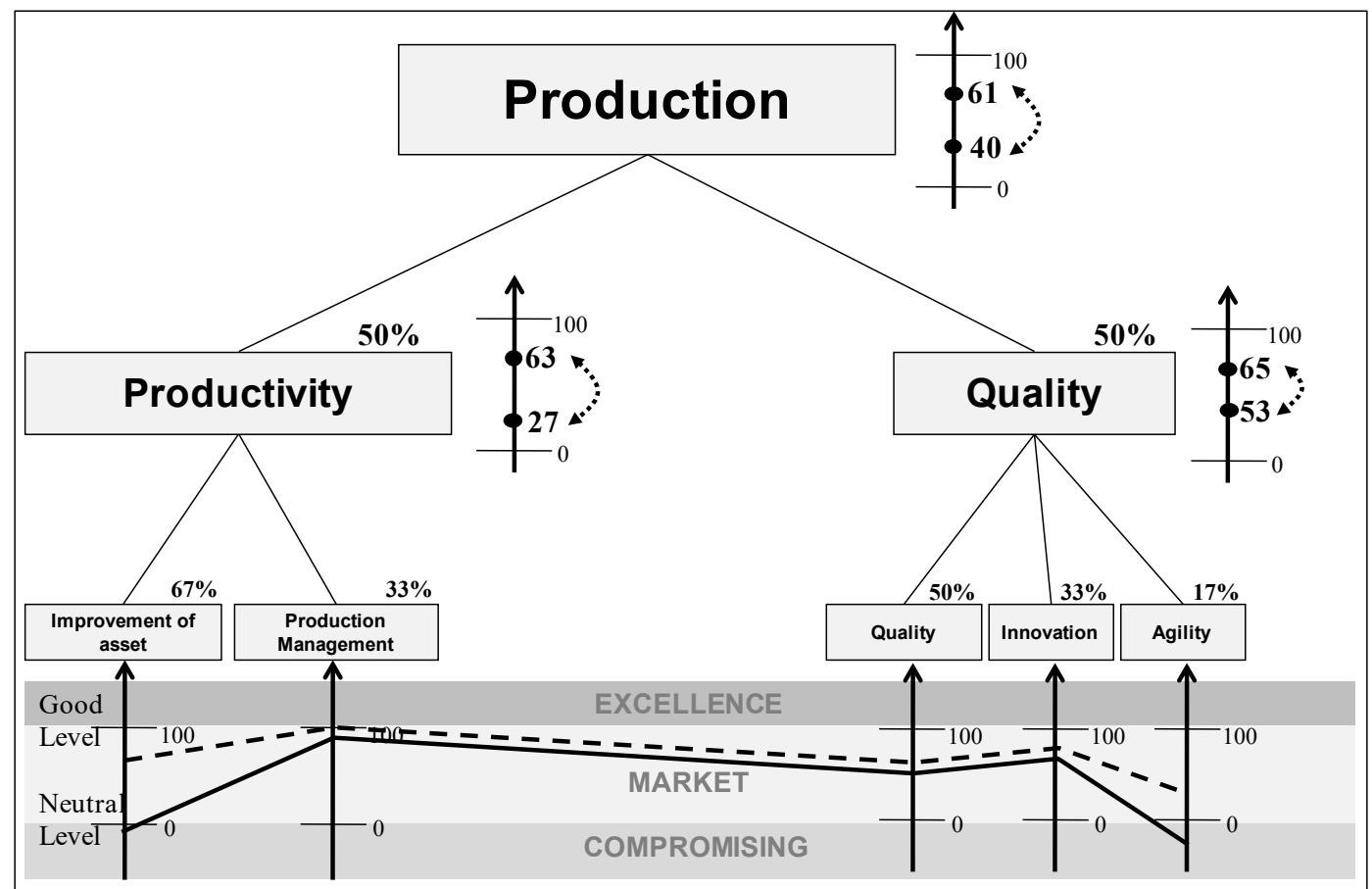

Figure 12: Impact profile of the status quo of the area of products and the profile impact after strategy deployment Source: Research data.

Legend: Status quo _ _ _ _ _ _ _ _ Performance with the implementation of the strategy

production director in the management of the productive operations of a furniture industry, through (i) the identification of factors considered important by the production director for evaluating the performance of the productive operations, (ii) the measurement of each criterion for performance evaluation, (iii) the integration of the criteria to enable performance evaluation at the tactical and strategic levels and (iv) the management of the improvement actions of productive operations.

The results indicate that it was possible to develop a model of performance evaluation for the particular productive operations of Marel Furniture Industry SA through the Multicriteria Methodology for Constructivist Decision Support (MCDA-C). The model identified 27 performance indicators (2 financial indicators and 25 non-financial indicators) that allowed the performance evaluation of the productive operations of the industry. The constructed indicators evaluated the following fundamental points of view: productivity and quality. The main aspects evaluated in relation to productivity were the improvement of assets and production management. With regard to quality, the aspects evaluated were quality, innovation and agility. It is worth noting that these classifications are groups from concepts oriented differently to action, thereby achieving the first specific objective of this research.
Revisiting the specific objective (ii) - building ordinal and cardinal scales for the identified indicators - reference is made to Figures 5, 6 and 7, which allow the visualization of the scales. The scope of the specific objective (iii) - to trace the performance profile and evaluate the local and global performance - can be seen in Figure 11. From the constructed model, and illustrated by Figure 11, it was possible to identify the indicators that need improvement actions, thereby achieving the specific objective (iv). It is noted that, within the scope of specific objective (iv), developed in the recommendations phase, strategies were drawn up that might make the performance pass from the status quo to superior performance after implementing the strategy. At this stage, we used the information and knowledge generated during the construction of the model to support the policy inherent in the productive operation of the organization. The illustration of this step can be seen in Figure 12.

In short, the research allowed the construction of a performance evaluation model to support the production director in the management of productive operations of Marel Furniture Industry SA, which was constructed showing the particularities of the object of the studied company. With the model, the manager will be able to manage the productive operations at the strategic, tactical and operational levels. 
The constructed PE model permits the construction, establishment and dissemination of knowledge through the identification, organization, measurement and integration of the aspects of the productive context deemed relevant to measure and manage the performance of the organization goals.

It is worth mentioning that the model has legitimacy for the studied company, because the values and preferences of the director of the production company were considered and therefore the particular strategies of the organization.

We suggest for further research the application of the MCDA-C tool to other companies, in order to consolidate it as a viable PE methodology for productive operations.

\section{REFERENCES}

Atkinson, R., Crawford, L. and Ward, S. (2006), "Fundamental uncertainties in projects and the scope of project management", International Journal of Project Management, Vol. 24 No. 8, pp. 687-698.

Azevedo, R.C.; Ensslin, L; Lacerda, R.T.O.; França, L.A.; Gonzalez, C.J.I.; Jungles, A.E and Ensslin, S.R. (2011), "Avaliação de Desempenho no Processo de Orçamento de uma Obra de Construção Civil", Ambiente Construído (Online), Vol. 11 No.1, pp. 85-104, 2011.

Baldwin, J.S., Allen, P.M. and Ridgway, K. (2010), “An evolutionary complex systems decision-support tool for the management of operations", International Journal of Operations \& Production Management, Vol. 30 No 7, pp. 700-720.

Bana e Costa, C.A., Ensslin, L., Correa, E.C. and Vansnick, J.-C. (1999), "Decision aiding systems in action: integrated application in a multicriteria decision aid process", European Journal of Operational Research, Vol. 113 No. 2, pp. 315-335.

Bortoluzzi, S.C., Ensslin, S.R. and Ensslin, L. (2010), "Avaliação de Desempenho dos Aspectos Tangíveis e Intangíveis da Área de Mercado: estudo de caso em uma média empresa industrial", RBGN Revista Brasileira de Gestão de Negócios, Vol. 12 No. 37, pp. 425-446.

Bortoluzzi, S.C., Ensslin, S.R. and Ensslin, L. (2011), “Avaliação de Desempenho Multicritério com Apoio à Gestão de Empresas: aplicação em uma empresa de serviços", Revista Gestão \& Produção, Vol. 18 No. 3, pp. 633-650.

Cossette, P. and Audet, M. (1992), "Mapping of an idiosyncratic schema", Journal of Management Studies, Vol. 29 No. 3, pp. 325-348.

Da Rosa, F.S., Ensslin, S.R, Ensslin, L. and Lunkes, R.J. (2012), "Environmental disclosure management: a constructivist case", Management Decision, Vol. 50 No. 6, pp. 1117-1136.
De Meyer, A., Loch, C.H. and Pich, M.T. (2002), "Managing project uncertainty: From variation to chaos", MIT Sloan Management Review, Vol. 43 No. 2, pp. 60-67.

Dvir, D. and Lechler, T. (2004), "Plans are nothing, changing plans is everything: the impact of changes on project success", Research Policy, Vol. 33 No. 1, pp. 1-15.

Eden, C. "1988", "Cognitive mapping”, European Journal of Operational Research, Vol. 36 No. 1, pp. 1-13.

Eden, C., Jones, S. and Sims, D. (1983), Messing about in problems, Pergamon Press, New York, NY.

Ensslin, L., Dutra, A. and Ensslin, S.R. (2000), "MCDA: a construtivist approach to the management of human resources at a governmental agency", International Transactions in Operational Research, Vol. 7 No. 1, pp. 79-100.

Ensslin, L., Giffhorn, E., Ensslin, S.R., Petri, S.M. and Vianna, W.B. (2010), "Avaliação do Desempenho de Empresas Terceirizadas com o Uso da Metodologia Multicritério de Apoio à Decisão- Construtivista", Revista Pesquisa Operacional, Vol. 30 No. 1, pp. 125-152.

Ensslin, L., Montibeller, G.N. and Noronha, S.M. (2001), Apoio à Decisão: Metodologias para Estruturação de Problemas e Avaliação Multicritério de Alternativas, Ed. Insular, Florianópolis, SC.

Fiol, C.M. and Huff, A.S. (1992), "Maps for managers: where are we? Where do we go from here?", Journal of Management Studies, Vol. 29 No. 3, pp. 267-286.

Frost, B. (1999), Performance Metrics: The New Strategic Discipline, Strategy \& Leadership, Chicago.

Goodwin, P. and Wright, G. (1998), Decision Analysis for Management Judgment. John Wiley \& Sons, Chichester.

Gupta, Y.P. and Somers, T.M. (1996), "Business strategy, manufacturing flexibility, and organizational performance relationships: a path analysis approach", Production and Operations Management, Vol. 5 No. 3, pp. 204-233.

Hopp, W.J., Iravani, S.M. and Shou, B. (2007), "A Diagnostic Tree for Improving Production Line Performance", Production and Operations Management, Vol. 16 No. 1, pp. 77-92.

Kaplan, R.S. and Norton, D.P. (2000), "Having trouble with your strategy? Then map it", Harvard Business Review, Vol. 78 No 5, pp. 167-176.

Keeney, R.L. (1992), Value Focused-Thinking: A Path to Creative Decision-making, Harvard Univ. Press, Cambridge.

Lacerda, R.T.O., Ensslin, L. and Ensslin, S.R. (2011), "A performance measurement framework in portfolio management: a constructivist case", Management Decision, Vol. 49 No. 4, pp. 648-668.

Lakatos, I. (1974), Falsification and the methodology of research programmes, in: 1. Lakatos and Musgrave (eds.). Cri- 
ticism and the Growth of Knowledge, Cambridge University Press. Cambridge.

Landry, M.A. (1995), "Note on the Concept of 'Problem", Organization Studies, Vol 16 No. 2, pp. 315-343.

Lima, E.P., Costa, S.E.G., and Angelis, J.J. (2008), “Framing Operations and Performance Strategic Management System Design Process", Brazilian Journal of Operations \& Production Management, Vol. 5 No. 1, pp. 23-46.

Pich, M.T., Loch, C.H. and Meyer, A.D. (2002), "On uncertainty, ambiguity, and complexity in project management", Management Science, Vol. 48 No. 8, pp. 1008-1023.

Quezada, L.E., Córdova, F., Palominos, P. and O'Brien, C. (2006), "Conceptual Model for the Generation of Performance Measures in Manufacturing Firms", Brazilian Journal of Operations \& Production Management, Vol. 3 No. 2, pp. 21-34.
Roberts, F.S. (1979), Measurement Theory. In: ROTA, G. C. (Ed.) Encyclopedia of mathematics and its applications, v. 7, Addison-Wesley Publishing Company, London.

Roy, B. (1993), "Decision science or decision-aid science?" European Journal of Operational Research, Vol. 8 No. 1, pp. 184-203.

Roy, B. (1994), "On operational research and decision aid", European Journal of Operational Research, Vol. 73 No. 1, pp. 23-26.

Roy, B. (1996), Multicriteria Methodology for Decision Aiding. Kluwer Academic Pub, Dordrecht.

Thiry, M. (2002), Project Management Pathways; University of Technology Sidney.

Vincke, P. (1992), Multicriteria Decision-aid. JohnWiley \& Sons. 